\title{
Perceived Parent-Child Interaction and Boys Self-Esteem in Two Cultural Contexts
}

Viktor Gecas

Washington State University

Darwin L. Thomas

Brigham Young University

Andrew Weigert

Follow this and additional works at: https://scholarsarchive.byu.edu/facpub

Part of the Religion Commons

\section{Original Publication Citation}

"'"'Perceived Parent-Child Interaction and Boys Self-Esteem in Two Cultural Contexts,"'" International Journal of Comparative Sociology 11 (3):317-24 (with V. Gecas and A.J. Weigert)."

\section{BYU ScholarsArchive Citation}

Gecas, Viktor; Thomas, Darwin L.; and Weigert, Andrew, "Perceived Parent-Child Interaction and Boys SelfEsteem in Two Cultural Contexts" (1970). Faculty Publications. 5690.

https://scholarsarchive.byu.edu/facpub/5690

This Peer-Reviewed Article is brought to you for free and open access by BYU ScholarsArchive. It has been accepted for inclusion in Faculty Publications by an authorized administrator of BYU ScholarsArchive. For more information, please contact ellen_amatangelo@byu.edu. 


\title{
4. Perceived Parent-Child Interaction and Boys' Self-Esteem in Two Cultural Contexts
}

\author{
VIKTOR GEGAS \\ Washington State University, U.S.A. \\ DARWIN L. THOMAS \\ Washington State University, U.S.A. \\ ANDREW WEIGERT \\ University of Notre Dame, U,S.A.
}

\section{Introduction}

The problem under consideration in the present paper deals with the relationship between parent-child interaction patterns and the child's self esteem. The relationship between these variables will be examined in the context of samples drawn from two societies: Saint Paul, Minnesota and San Juan, Puerto Rico. ${ }^{1}$ It is hoped that a cross-cultural investigation of the effects of parent-child interaction on the child's self esteem will enable us to make a more precise statement about the nature of this relationship. ${ }^{2}$

Symbolic interaction theory in sociology offers perhaps the most extensive explanation of the relationship between social factors (interaction patterns) and the development of the self. In the tradition of G. H. Mead (1934) and C. H. Cooley (1902) the self is defined as a symbolic construct and explained in terms of the reflected appraisals of others. In coining the concept "looking-glass self," Cooley emphasized the reflective nature of the self, i.e., one's social reference is determined by his imagination of how he appears in the minds of others. Sullivan (1947) defined the self as an organization of conceptions and perceptions whose primary purpose is to decrease anxiety which results from the disapproval of others. Rogers (1951), from a psychiatric perspective, suggested that it is the child's experience of others' awareness and reaction to him which is responsible for the differentiation of his experience into "that which he is" and "that which others are." Thus, through evaluational interaction with others, the individual forms an organized pattern of perceptions about his own nature. perceptions of both negative and positive value.

It seems reasonable to expect that parents are among the most important significant others for the child and consequently have a substantial influence on the development of the child's self-system. Parents are the first objects of the child's affection. He is dependent on them for the satisfaction of his most basic needs. The interaction between parents and child comes early, is constant, and

1 The data for this study are drawn from a cross-cultural study of parent-child interaction and adolescent personality and behavior conducted by Darwin Thomas and Andrew Weigert and supported in part by NSF Grants (GS 1801, GS 2650) and Washington State University Research Grants-in-Aid. Their research included samples of students from Catholic schools in St. Paul, Minnesota; New York, New York; San Juan, Puerto Rico; and Merida, Mexico. Two of these samples, St. Paul and San Juan, were selected for the present report.

2 We wish to thank Professor Murray A. Straus for reading and criticizing earlier drafts of this paper. 
is intimate. It is logical, therefore, that the parents' evaluations of the child, as perceived by the child, will have a great influence on his self esteem.

There has been enough research supporting the direct relationship between social interaction and self esteem that at least the notion has a high degree of credibility. Research on the effect of parent-child interaction patterns on the child's self esteem is much scantier but points in the same direction. Helper (1958) collected data on self-evaluations of 74 8th and 9th graders in Illinois. $\mathrm{He}$ also gathered data on the parental evaluations of the child directly from one or both of the parents. Correlations between self-acceptance and acceptance by the parent indicated a similarity between parent's evaluations of their child and the child's self-evaluations.

Jourard and Remy (1955), using a sample of 99 undergraduate Emory University students, found that self-appraisals covary with a person's perception of his parents' appraisals of him. Furthermore, negative self-appraisals and perceived negative parental appraisals of the student's self were related to phychological insecurity.

Perhaps the most relevant study in this area is that by Rosenberg (1965) on parental interest and children's self-conceptions. His key independent variable was parental interest in the child, which he used as an indicator of parental evaluation. His subjects consisted of high school juniors and seniors selected from a stratified random sample of ten high schools in New York State. Rosenberg's findings are quite impressive. In all three areas of parental interest investigated, the data consistently show that parental indifference is associated with lower self-esteem in the child. Also, students who reported only punitive responses tended to have lower self-esteem than those who reported only supportive responses, but students who reported indifferent responses had lower self-esteem than either of these groups. Thise findings support the basic Meadian hypothesis that the self reflects the attitudes of significant others.

A number of investigators have maintained that the sex of the parent and the sex of the child are important factors which need to be considered in assessing the effect of parent-child interaction on the development of the child's self. Douvan and Gold (1966) in a review of the literature concluded that sexrole identity is likely to be central to an individual's total self-conception. The family emotional relationships are different for sons than for daughters. And the effect of mother is different from that of father on the child's self esteem. Empirical support for these notions is offered by Droppleman and Schaefer (1963) and Bronfenbrenner (1961).

Droppleman and Schaefer investigated the difference between boys' and girls' reports of parental behavior. They administered a parent behavior inventory to 85 male and 80 female students in a Catholic high school. The items comprised the components of parental nurturance and control. Mothers were reported significantly higher in nurturance than fathers by both boys and girls, and both reported the opposite sex parent as more "autonomy granting" than the parent of the same sex.

Bronfenbrenner also examined the influence of sex differences on parentchild interaction in a sample of 400 New York tenth graders. His findings suggest that within the family, boys and girls are in somewhat contrasting situations. Girls receive more affection, attention, and praise than boys, whereas boys are subjected to greater discipline, mainly from their fathers. Bronfen- 
brenner also found that a child is given more support by the parent of the opposite sex.

Taking these considerations dealing with sex differences into account, the effect of parental evaluation on the child's self esteem will be examined separately for each parent. However, since the present report deals only with a male sample of adolescents, the findings can only be generalized to boys. In subsequent reports of this research, a boy-girl comparison will be undertaken.

\section{Hypotheses}

In the present study, evaluations of the child by significant others (parents) will not be directly measured. However, the dimension of parental support is an indirect measure of parental appraisals of the child and should be similarly reflected in the child's self esteem. The following hypotheses were tested:

1) Parental support is positively related to the child's self esteem.

2) Father's support is more strongly related to the child's (boy's) self esteem than is mother's support.

If the propositions of symbolic interaction theory dealing with the self are true (they are usually stated in universalistic terms), they should be true for social contexts other than the United States. Unfortunately, the authors have found that comparative research on these variables is practically non-existent. ${ }^{1}$ One of the main objectives of the present study is to examine the relationship between parent-child interaction and the child's self esteem in two different cultural contexts. It is expected that the hypotheses stated above will hold for both Saint Paul, Minnesota and San Juan, Puerto Rico.

\section{Methodology}

Sample: The subjects for the study are 399 high school boys selected from a Catholic high school in St. Paul, Minnesota and in San Juan, Puerto Rico. The average age of the respondents is 16 years. Questionnaires were administered to the students in a group setting, either a classroom or an auditorium. Both samples are very similar with regard to parent's age $((X=43)$, parent's education $(\mathrm{X}=14 \mathrm{yrs}$.), and per cent Catholic $(90 \%-95 \%)$. They differ, however, on social class. A greater proportion of the fathers of San Juan students are in the upper-middle and middle class occupations ("technical or professional" and "proprietor or official") than were the fathers of the St. Paul students. The percentage differential for these occupations was $79 \%$ and $43 \%$ for San Juan and St. Paul respectively. Almost no lower class respondents were found for either sample: only $9 \%$ could be classified as lower class in St. Paul and $0 \%$ in San Juan, using father's occupation.

Measures: The independent variable, parental support, is measured by items taken from the instrument developed by Bronfenbrenner et al., which has been called the Bronfenbrenner Parent Behavior Questionnaire (BPB) (Rodgers, 1966). The BPB requires that the child answer questions about how his parents act toward him. The theoretical importance of the child's perception

1 There have been a number of cross-cultural studies dealing with related topics, such as, the effect of specific parentchild interaction patterns on the child's achievement motivation, anxiety level, sexual identification, agression, and other aspects of personality. But very little has been done cross-culturally with self-esteem. 
of his parents' behavior for understanding personality development has been emphasized by a number of investigators. Garmezy, Clarke, and Stockner (1961) claimed that it is the subject who interprets the inter-action between himself and his parents and for him it is his own definition of the situation that is most significant. Ausubel et al. (1954) note that parental behavior effects the child's ego development only to the extent and in the form in which he perceives it.

The short form of the $\mathrm{BPB}$ was designed to measure the three most important explanatory factors emerging out of the earlier work of the Cornell group. The factors are called "support," "control," and "punishment" and each is measured by the sum of four items. Only the "support" factor of the BPB will be considered in this paper. The following four items are the indices for this variable:

1) If I have any kind of a problem, I can count on her/him to help me out.

2) She/he says nice things about me.

3) She/he teaches me things I want to learn.

4) She/he makes me feel she/he is there if I need her/him.

The student was asked to respond to these items, both for his mother and father, on a five-point Likert-type scale ranging from "Never" to "Very often."

The reliability estimates, or average inter-item correlations, for the support factor are .73 for father and .69 for mother, and the correlation between parents is .55 (Rodgers, 1966). In addition to these average inter-item correlations of the Cornell group, test-retest stability correlation coefficients were obtained for a group of 29 girls. The mean item stability coefficient was .67 for the mother and .71 for the father.

The dependent variable, self evaluation of the child, was measured by items from Osgood's (1962, 1964) Semantic Differential. The "evaluation" factor was composed of three sets of adjectives: 1) friendly-unfriendly, 2) happy-sad, and 3) good-bad. The subject was asked to respond to these pairs of opposites on a five-point scale ranging from one of the adjectives to the other. The factor loadings for these items for Osgood's American sample are .88, .91, and .93 respectively. A test-retest reliability coefficient was computed for the same sample of 29 girls. The mean stability coefficient for the three self-evaluation items was, $\mathrm{r}=.55$.

\section{Results}

The results are presented in tables 1 through 3 . For each of these tables, the variables self evaluation and parental support have been trichotomized. The reason for trichotomizing rather than dichotomizing the variables was to retain as much information from the data as possible. That is, the trichotomized variable would permit a curvilinear relationship to show up, whereas this would be washed out if the variables were simply dichotomized. Furthermore, since the sample size is fairly large, there was little chance of having the cell frequencies too small to run $\mathrm{X}^{2}$ tests. Cut-off points for the values of each variable were determined by the frequency distribution for that variable. That is, cut-offs were made with an eye to equal frequencies for each of the three categories. The danger of using this procedure for establishing cut-off points is that it allows for intra-sample comparisons at the expense of inter-sample comparisons. However, since in the present study the frequency distributions 
for these variables are similar for both samples, the latter disadvantage is minimized.

The relationship between parental support and self evaluation for the St. Paul sample is presented in the first part of Table 1.

Table 1

Parental Support and Child's Self Evaluation by City

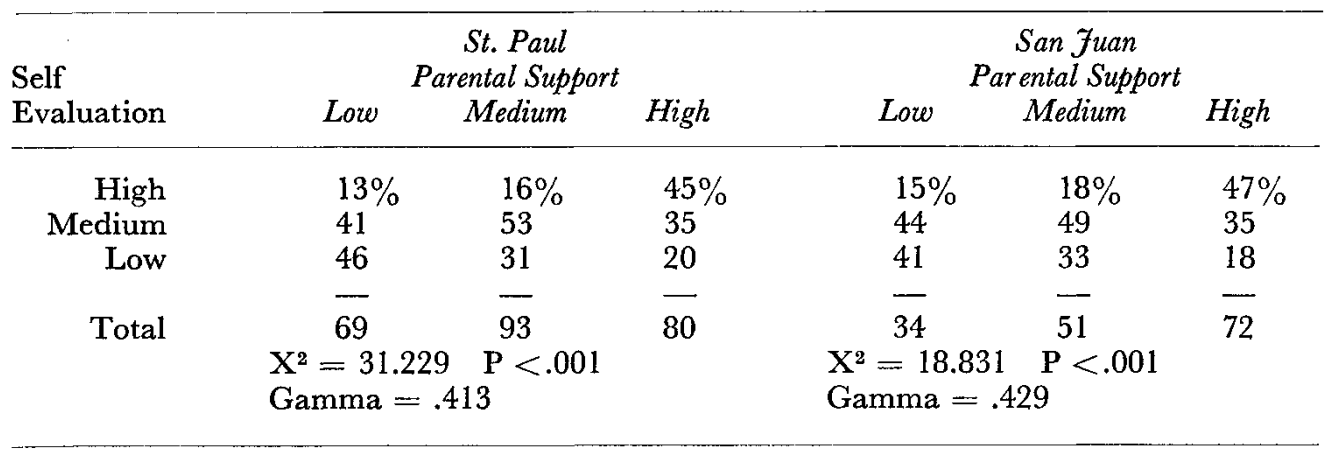

There seems to be a positive linear relationship between parental support and self evaluation. $45 \%$ of the high support students also had high self evaluation, compared to $16 \%$ of the medium support and $13 \%$ of the low support subjects. $53 \%$ of the medium support students had medium self evaluation, and $46 \%$ of the low support subjects (the highest proportion for this category) had low self evaluation. The $\mathrm{X}^{2}$ value was highly significant. But even more important than this was the relatively high measure of association, $\mathrm{G}=.413$.

Similar results were obtained for these variables for the San Juan sample. The second half of Table 1 shows that $47 \%$ of the high support subjects had high self esteem, compared to $18 \%$ and $15 \%$ for medium and low support subjects respectively. $49 \%$ of those classified as medium support also had medium self esteem. However, the highest category for low support was medium self esteem (44\%), and not low self esteem as expected. However, the

Table 2

Father Support and Child's Self Evaluation by City

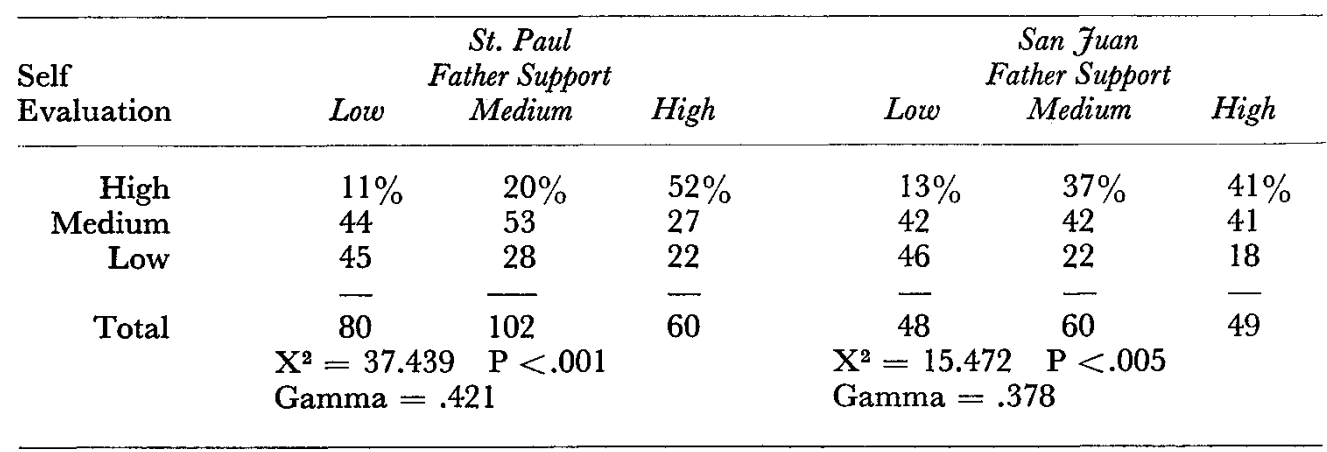


latter came in a close second with $41 \%$. The coefficient of association was relatively high, $\mathrm{G}=.43$.

In the next two tables parental support is differentiated into father support and mother support. The first half of Table 2 shows the relationship between self evaluation and father support for the St. Paul sample. 52\% of those who had high father support also had high self esteem, compared to $20 \%$ of those with medium support and only $11 \%$ of those with low paternal support. The medium support subjects were highest in the category medium self evaluation $(53 \%)$. And the biggest frequency for low support subjects was, expectedly, low self evaluation $(45 \%)$. The Gama coefficient was again relatively high at .421 .

The relationship wasn't as distinct for the San Juan sample, although it went in the expected direction. The second half of Table 2 shows an equal proportion of those high on father support were high and medium on self esteem ( $41 \%$ for both cells). The highest cell frequency for medium support was medium self evaluation (42\%), and for low support it was low self evalua-

Table 3

Mother Support and Child s Self Evaluation by City

\begin{tabular}{|c|c|c|c|c|c|c|}
\hline \multirow{2}{*}{$\begin{array}{l}\text { Self } \\
\text { Evaluation }\end{array}$} & \multicolumn{3}{|c|}{$\begin{array}{c}\text { St. Paul } \\
\text { Mother Support }\end{array}$} & \multicolumn{3}{|c|}{$\begin{array}{c}\text { San Fuan } \\
\text { Mother Support }\end{array}$} \\
\hline & Low & Medium & High & Low & Medium & High \\
\hline High & $12 \%$ & $18 \%$ & $45 \%$ & $13 \%$ & $19 \%$ & $44 \%$ \\
\hline Medium & 44 & 51 & 35 & 52 & 49 & 33 \\
\hline Low & 45 & 32 & 21 & 36 & 32 & 23 \\
\hline Total & $\begin{array}{c}\overline{69} \\
\mathrm{X}^{2}=28.71 \\
\mathrm{Gamma}=\end{array}$ & $16 \stackrel{\mathrm{P}}{\mathrm{P}<.001}$ & $\overline{78}$ & $\begin{array}{c}\overrightarrow{31} \\
\mathrm{X}^{2}=14.4 \\
\text { Gamma }=\end{array}$ & $\begin{array}{l}\quad \overrightarrow{47} \\
348\end{array}$ & $\overline{79}$ \\
\hline
\end{tabular}

tion $(45 \%)$. However, the differences between the frequencies for these cells wasn't that great, even though they went in the expected direction. Nevertheless, the $\mathrm{X}^{2}$ value was significant at the .005 level, and Gamma $=.378$.

The third table examines the relationship between mother support and self evaluation. A strong positive relationship is indicated for the St. Paul sample. $45 \%$ of the high mother support subjects were also high in self evaluation, compared to $18 \%$ of the medium support and $12 \%$ of the low support subjects. $51 \%$ of the medium support were also medium on self evaluation, and $45 \%$ of the low support were low on self evaluation (although the medium and low self evaluation cells for low support were very close proportionately). $\mathrm{X}^{2}$ was significant at the .001 level, and Gamma was a respectable .403.

The relationship between mother support and self esteem is not as strong for the San Juan sample, but is similar. The second half of Table 3 shows that $44 \%$ of the high support cases were also high on self esteem and $49 \%$ of the medium supports were medium on self esteem. For the low supports, however, the most common category of self esteem was not low, as expected, but medium $\left(52 \%\right.$ and $36 \%$ for medium and low self esteem respectively). $\mathrm{X}^{2}$ was significant at the ,01 level, and Gamma was equal to .348. 
For a measure of the degree of difference between the association of father support and child's self esteem and that of mother support and child's self esteem, the Gamma coefficients for these relationships in Tables 2 and 3 can be compared. For the St. Paul sample, Gamma $=.421$ for father support and .403 for mother support and child's self esteem. For the San Juan sample, Gamma $=.378$ for father support and .348 for mother support and child's self esteem.

\section{Discussion}

The hypotheses dealing with parental support and child's self esteem are strongly supported by the data from both St. Paul, Minnesota and San Juan, Puerto Rico. The significance levels for these relationships range from .01 to .001 , and the degree of association (Gamma) between these variables range from .348 to .429 . The differences between the degree of association of father support and child's self esteem and that of mother support and child's self esteem are not very large for either sample, but are in the hypothesized direction: father support is more strongly associated with child's self esteem than is mother support.

The relationships between parental support and child's self esteem are very similar in the St. Paul and San Juan samples. In each case the direction of a relationship is the same. However, the degree of association between father support and child's self esteem and mother support and child's self esteem is greater for St. Paul than for San Juan, even though the gross measure parental support and child's self esteem is greater for San Juan than for St. Paul. These differences, however, are not large enough to warrant speculation. What is more surprising are the similarities in the relationships between these variables for the two samples, especially since the samples had a somewhat different social class composition, and also considering the problems involved in cross-cultural analysis. The two problems which most often plague cross-cultural research, translation and conceptual equivalence of the instrument, appear to have been at a minimum in the present study.

There is a possibility that class was operating as a confounding variable on the relationship between parental support and the child's self esteem. To check for this possibility correlation coefficients were obtained for social class, measured by father's occupation and mother's and father's education, and parental support; and also between self esteem and social class, for both societies. There was very little or no relationship found between the dependent variable, self esteem, and any of the indicators of social class. The correlation coefficients ranged from -.05 to .14. The association was a little stronger between social class and the independent variables (mother support, father support, and parental support), but these were quite low also. They ranged from .04 to .29, being slightly higher for Saint Paul than San Juan. On the basis of these correlation coefficients, we feel it is safe to assume that the relationship between parental support and the child's self esteem is not spurious because of the effect of social class.

It may be premature to generalize the relationships between parental evaluation, father evaluation, and mother evaluation, and boy's self esteem found in this study to all human societies and all social conditions. Nevertheless, finding this similar a set of relationships to exist in two societies gives empirical 
weight to some of the general symbolic interaction notions concerning the development of the self.

\section{REFERENCES}

Ausubel, D. P., E. E. Balthazar, Irene Rosenthal, L. S. Blackman, S. H. Schpoont, and Joan Welkowitz. "Perceived Parent Attitudes as Determinants of Children's Ego Structure," Child Development, 1954, 25, 173-184.

Bronfenbrenner, Urie. "Some Familial Antecedents of Responsibility and Leadership in Adolescents," In Luigi Petrullo and Bernard M. Bass (Eds.), Leadership and Interpersonal Behavior, New York: Holt, Rinehard, and Winston, 1961, pp. 239-272.

Bronfenbrenner, Urie. "Toward a Theoretical Model for the Analysis of Parent-Child Relationships," In John G. Glidewell (Ed.), Parental Attitudes and Child Behavior, Spingfield, Ill.: Charles C. Thomas, 1961, pp. 90-109.

Cooley, Charles H. Human Nature and the Social Order, New York: Charles Scribners, 1902.

Douvan, Elizabeth and Martin Gold. "Modal Patterns in American Adolescence," In Martin L. Hoffman and Lois W. Hoffman (Eds.), Review of Child Development Research, Vol. 11, New York: Russell Sage Foundation, 1966, pp. 469-528.

Droppleman, Leo F. and Earl S. Schaefer. "Boys' and Girls' Reports of Maternal and Paternal Behavior," Fourn. of Abnorm. and Soc. Psych., 1963, 67, 648-654.

Garmezy, N., A. R. Clarke, and C. Stockner. "Child Rearing Attitudes of Mothers and Fathers as Reported by Schizophrenic and Normal Patients," J. of Abnorm. and Soc. Psychol., 1961, $63,176-182$.

Helper, Malcolm N. "Parental Evaluations of Children and Children's Self Evaluations," 7. of Abnorm. and Soc. Psychol., 1958, 56, 190-194.

Jourard, Sidney M. and Richard M. Remy. "Perceived Parental Attitudes, the Self, and Security," 7. of Consult. Psychol., 1955, 19, 364-366.

Mead, George H. Mind, Self, and Society, Chicago: University of Chicago Press, 1934.

Osgood, Charles E. "Studies on the Generality of Affecive Meaning Systems," American Psychologist, 1962, 16, 10-28.

Osgood, Charles E. "Semantic Differential Technique in the Comparative Study of Cultures," American Anthropologist, 1964, 66, 171-200.

Rodgers, Robert E. Cornell Parent Behavior Description - The proposed short form. Unpublished report, Cornell University, 1966.

Rogers, Carl. Client-Centered Therapy, Boston: Houghton-Mifflin, 1951.

Rosenberg, Morris. Society and the Adolescent Self-Image, Princeton, New Jersey: Princeton University Press, 1965.

Sullivan, Harry Stack. Conceptions of Modern Psychiatry, Washington, D.G.: William Alanson White Psychiatric Foundation, 1947. 